\title{
Arbeidsmarktprognoses De Achterhoek 2017-2022
}

Citation for published version (APA):

Peeters, T., \& Cörvers, F. (2018). Arbeidsmarktprognoses De Achterhoek 2017-2022. ROA. ROA Fact Sheets No. 010E https://doi.org/10.26481/umarof.2018010E

Document status and date:

Published: 01/01/2018

DOI:

10.26481/umarof.2018010E

Document Version:

Publisher's PDF, also known as Version of record

\section{Please check the document version of this publication:}

- A submitted manuscript is the version of the article upon submission and before peer-review. There can be important differences between the submitted version and the official published version of record.

People interested in the research are advised to contact the author for the final version of the publication, or visit the DOI to the publisher's website.

- The final author version and the galley proof are versions of the publication after peer review.

- The final published version features the final layout of the paper including the volume, issue and page numbers.

Link to publication

\footnotetext{
General rights rights.

- You may freely distribute the URL identifying the publication in the public portal. please follow below link for the End User Agreement:

www.umlib.nl/taverne-license

Take down policy

If you believe that this document breaches copyright please contact us at:

repository@maastrichtuniversity.nl

providing details and we will investigate your claim.
}

Copyright and moral rights for the publications made accessible in the public portal are retained by the authors and/or other copyright owners and it is a condition of accessing publications that users recognise and abide by the legal requirements associated with these

- Users may download and print one copy of any publication from the public portal for the purpose of private study or research.

- You may not further distribute the material or use it for any profit-making activity or commercial gain

If the publication is distributed under the terms of Article $25 \mathrm{fa}$ of the Dutch Copyright Act, indicated by the "Taverne" license above, 
Maastricht University $\&$ ROA

Arbeidsmarktprognoses Achterhoek 2017-2022

Tim Peeters

Frank Cörvers

\section{ROA Fact Sheet}

ROA-F-2018/10E

Researchcentrum voor Onderwijs en Arbeidsmarkt | ROA Research Centre For Education and the Labour Market / ROA 


\section{Arbeidsmarktprognoses Achterhoek 2017-2022}

Inleiding

Als onderdeel van het Project Onderwijs-Arbeidsmarkt (POA) stelt het ROA sinds 2013 tweejaarlijkse regionale arbeidsmarktprognoses op die tegemoet komen aan de toenemende belangstelling voor regionale arbeidsmarktinformatie. Binnen dit kader past ook voorliggende factsheet met arbeidsmarktprognoses voor de Achterhoek. Deze prognoses bestrijken de periode 20172022 en worden weergegeven voor 24 opleidingscategorieën die verdeeld zijn over zes opleidingsniveaus. Waar mogelijk worden de prognoses vergeleken met deze voor Gelderland als geheel, en wordt er een relatie gelegd met zowel de sector-als opleidingsspecialisatie van de werkgelegenheid in de verschillende regio's. De interpretatie van de prognoses gebeurt steeds vanuit het perspectief van schoolverlaters en werkzoekenden.

De prognoses voor de hele provincie Gelderland evenals een leeswijzer kunnen gevonden worden in de factsheet met nummer ROA-F-2018/IO. Onderstaande kaart geeft aan hoe Gelderland is samengesteld uit de verschillende arbeidsmarktregio's, en de overzichtstabel laat de verschillende gemeenten zien die in de Achterhoek gelegen zijn. Zie ten slotte Tekstbox I voor definities van de in deze factsheet gebruikte variabelen.

Arbeidsmarktregio's binnen Gelderland

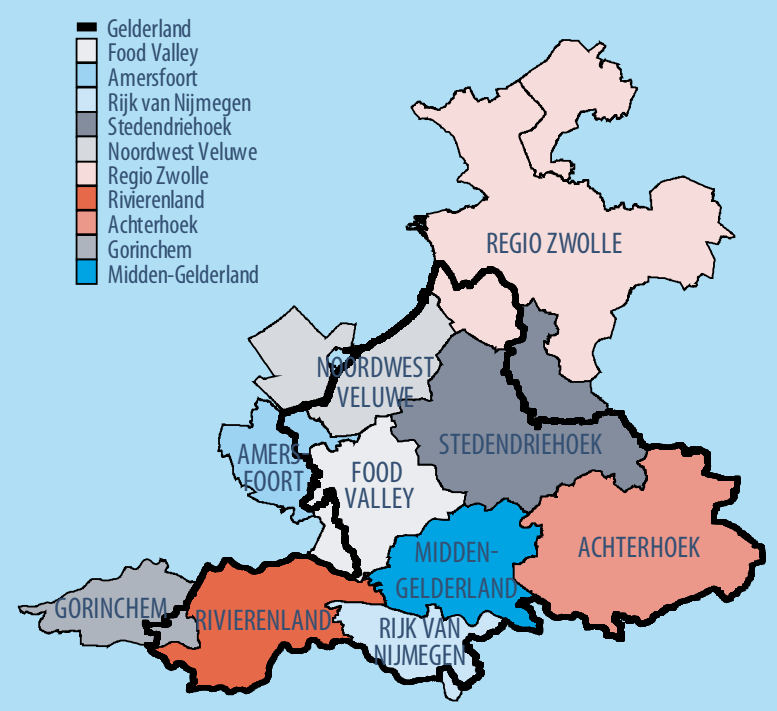

Gemeenten in de Achterhoek

Aalten

Berkelland

Bronckhorst

Doetinchem

Montferland

Oost Gelre

Oude IJsselstreek

Winterswijk
Prognoses en actuele arbeidsmarktcijfers naar opleidingsniveau

Zoals blijkt uit Tabel I wordt voor de Achterhoek op geaggregeerd niveau met een ITAvan I, O2 een lichtvraagtekort verwacht. Dit is hoofdzakelijk het gevolg van een beperkte verwachte uitbreidingsvraag van gemiddeld o,3\% per jaar. Daarmee zal de procentuele werkgelegenheidstoename in de Achterhoek naar verwachting bijna drie maal kleiner zijn dan het Gelderse gemiddelde.

Schoolverlaters van mbo $2 / 3$ en mbo 4 kennen matige arbeidsmarktperspectieven die niet alleen resulteren uit een beperkte uitbreidingsvraag, maar eveneens uit een relatief kleine vervangingsvraag. Voor wo neemt de beperkte uitbreidingsvraag van $0,3 \%$ per jaar niet weg dat dit opleidingsniveau binnen Gelderland in de Achterhoek met een ITA van 0,87 met voorsprong de beste vooruitzichten voor wo-gediplomeerden kent. Dit is het gevolg van een substantiële vervangingsvraag (gemiddeld 5,9\% per jaar). Opvallend is verder dat de Achterhoek een zeer geringe proportie wo-gediplomeerden kent in vergelijking met Gelderland als geheel. Wel werken zij in deze arbeidsmarktregio het vaakst voltijds. De goede vooruitzichten verschillen sterk met deze voor hbo-schoolverlaters, welke met een ITA van I,O5 slechts redelijke perspectieven hebben als gevolg van een zeer lage uitbreidingsvraag ( $0,1 \%$ per jaar) en een vrij hoge arbeidsmarktinstroom (3,8\% per jaar).

Opvallend is datschoolverlatersvan zowel basisonderwijs/ vmbo als wo goede arbeidsmarktperspectieven hebben volgens de ITA. De gunstige perspectieven voor basisonderwijs en vmbo dienen echter met enige voorzichtigheid geïnterpreteerd te worden. Een aanzienlijk deel van de vraag naar personen met basisonderwijs of vmbo als opleidingsachtergrond heeft namelijk betrekking op laagbetaalde en kleine banen. Dit kan afgeleid worden van het relatief lage uurloon (13,7 euro), het lage gemiddeld aantal gewerkte uren per week $(25,5)$ en het hoge aandeel van studenten en scholieren (24\%). Bovendien gaat het vaak om flexibele banen met weinig doorgroeimogelijkheden. Enerzijds blijkt dit uit het lage percentage dat voltijds en vast in dienst is. Anderzijds komt dit ook tot uiting in het slechte loopbaanperspectief. De variabele "typering loopbaan", die per opleidingsniveau de loongroei tussen ca. 25 en 45 jaar (berekend voor Nederland als geheel) weergeeft in 2016, is namelijk het minst gunstig voor laagopgeleiden, en het meest gunstig voor havo/vwo. ${ }^{.}$Deze laatste groep bestaat

I De indicator voor loopbaanperspectief wordt berekend aan de hand van het verschil in bruto uurloon van werkenden in de leeftijdsgroep 20-29 jaar en 40-49 jaar. Voor een argumentatie, zie Fouarge, D., Kriechel, B., \& Dohmen, T. (20I4), Occupational sorting of school graduates: The role of economic preferences, Journal of Economic Behavior \& Organization, 106, 335-351. 
mogelijk deels uit mensen die geen hogere opleiding hebben afgemaakt omdat ze door hun persoonlijke capaciteiten uitstekende kansen op de arbeidsmarkt hadden.

Verder is van belang dat de groep van laagopgeleiden met basisonderwijs of vmbo heel heterogeen is: niet alleen scholieren, maar ook voortijdig schoolverlaters zonder startkwalificatie (minimaal mbo 2 of havo), schoolverlaters van het speciaal onderwijs en arbeidsgehandicapten. Bij het aangegeven goede arbeidsmarktperspectief is geen rekening gehouden met de mogelijke sociale, fysieke en cognitieve beperkingen van mensen binnen deze groep.

\section{Sectorspecialisatie}

De Achterhoekse sectorspecialisatie ${ }^{2}$, weergegeven in Figuur I, wijkt vaak aanzienlijk af van deze van Gelderland als geheel. De sector landbouw, bosbouw en visserij kent in deze arbeidsmarktregio de grootste sectorspecialisatiecoëfficiënt. Daarnaast heeft de Achterhoek een uitgesproken focus op industrie, niet alleen in vergelijking met Nederland maar eveneens ten opzichte van de andere arbeidsmarktregio's. Alle industriesectoren kennen namelijk een werkgelegenheidsaandeel dat meer dan $50 \%$ groter is dan dat van Nederland. Ook de bouwnijverheid en de welzijnssector kennen een relatief groot aandeel werkenden. Dit is echter niet het geval voor de sector cultuur, sport en recreatie, informatie en communicatie en de zorgsector. Bovendien zijn sectoren die relatief veel gediplomeerde schoolverlaters van hogere economische richtingen aanwerven dikwijls ondervertegenwoordigd, zoals specialistische zakelijke dienstverlening, financiële dienstverlening en onroerend goed en openbaar bestuur en overheidsdiensten.

\section{Arbeidsmarktperspectieven naar opleidingscategorie}

De prognoses naar opleidingsniveau uit de eerste paragraaf kunnen verder uitgesplitst worden naar opleidingscategorie. Dit is weergegeven in Figuur 2, die per opleidingscategorie binnen het lager en middelbaar (beroeps)onderwijs toont hoe de totale arbeidsvraag en het totale arbeidsaanbod zich naar verwachting de komende zes jaar in de Achterhoek zullen verhouden. Figuur 3 doet hetzelfde voor het hoger onderwijs.

De kleuren bakenen de gebieden af die corresponderen met de vijf eerder besproken ITA-typeringen voor schoolverlaters, gaande van slecht (rood en ITA > I,I5) tot zeer goed (grijs en ITA $\leq 0,85$ ). Deze kunnen geïnterpreteerd worden als kwalitatieve aanduidingen van de toekomstige arbeidsmarktperspectieven. Voor de punten op de middelste diagonale lijn zijn verwachtevraag en aanbod aan elkaargelijk,

2 Gebaseerd op de werkzame beroepsbevolking uit de Enquête Beroepsbevolking (EBB), inclusief zelfstandigen. wat correspondeert met een ITA gelijk aan I. Bijvoorbeeld, voor hbo techniek bedragen het totale aanbod en de totale vraag over zes jaar respectievelijk (afgerond) $28 \%$ en $38 \%$. Deze waarden impliceren een ITA van 0,93 , zodat hbo techniek zich bevindt in het donkerblauwe gedeelte met het perspectief "goed". ${ }^{3}$ Merk op dat deze ITA een gemiddelde betreft van de opleidingscategorie hbo techniek, en dat er variatie kan bestaan in de arbeidsmarktperspectieven van de onderliggende opleidingstypes.

De prognoses naar opleidingscategorie in Figuur 2 tonen allereerst dat alle mbo-richtingen afgezien van mbo 4 techniek tijdens de prognoseperiode naar verwachting te maken zullen krijgen met een overaanbod van arbeid. Dit is in het bijzonder het geval voor mbo $2 / 3$ groen, mbo $2 / 3$ economie en mbo 4 economie. Het aanbodoverschot van mbo $2 / 3$ techniek-gediplomeerden blijft daarentegen relatief beperkt. De bescheiden vraag naar mbo-gediplomeerden staat in contrast met de substantiële vraag naar afgestudeerden uit de meeste wo-richtingen. Figuur 3 toont dat die grote vraag hoofdzakelijk geldt voor wo techniek en wo gedrag en maatschappij, welke vanwege een hoge vervangingsvraag de komende zes jaar een totale vraag zullen kennen die bijna even groot is als de huidige werkgelegenheid. Een relatief kleine vraag wordt voorzien voor schoolverlaters van wo onderwijs, die als gevolg daarvan slechts matige perspectieven hebben.

Hoewel het procentuele aanbod van hbo-gediplomeerden naar verwachting weinig zal verschillen van dat van wo-gediplomeerden, zal de vraag naar hbo-gediplomeerden dikwijls wel significant kleiner zijn. Dit maakt dat de arbeidsmarktvooruitzichten voor hbo-opleidingscategorieën meestal wat matiger uitvallen. Hbo economie heeft zelfs een slecht arbeidsmarktperspectief vanwege een bijzonder kleine verwachte vraag. De slechte perspectieven voor hbo economie zijn deels een gevolg van het feit dat sectoren die intensief gebruik maken van gediplomeerde schoolverlaters van de onderliggende opleidingen relatief ondervertegenwoordigd zijn in de Achterhoek (zie Figuur I). Aangezien ten slotte de technische opleidingen, afgezien van mbo $2 / 3$ techniek, minstens goede arbeidsmarktperspectieven hebben, zullen de voor de Achterhoek belangrijke industriële sectoren vermoedelijk gaan kampen met tekorten voor technisch opgeleiden.

\section{Relatie arbeidsmarktperspectieven en specialisatie naar opleiding}

Figuur 4 toont de relatie tussen de verwachte arbeidsmarktperspectieven (ITA) voor de verschillende opleidingscategorieën over de periode 20I7-2022 en de mate

3 De berekening van de ITA is niet louter een deling van aanbod en vraag, aangezien teller en noemer nog dienen vermeerderd te worden met Ioo. 
waarin de Achterhoek in deze opleiding "gespecialiseerd" is. Deze laatste variabele is gelijk aan de ratio van het aandeel werkzame personen met een bepaalde opleidingscategorie die in de Achterhoek wonen ten opzichte van het aandeel van die opleidingscategorie in het Nederlandse totaal. Indien de specialisatiecoëfficiënt voor een opleidingscategorie groter is dan I, betekent dit dus dat de Achterhoek in verhouding tot Nederland een groter aandeel van mensen met deze opleiding kent. Bijvoorbeeld, de opleidingsspecialisatiecoëfficiënt van I,54 die hoort bij mbo 4 zorg en welzijn impliceert dat het aandeel van deze opleidingscategorie in de Achterhoek 54\% groter is dan het aandeel van deze opleidingscategorie in Nederland als geheel.

De figuur vertoont een vrij positief lineair verband, wat betekent dat de oververtegenwoordiging van een opleidingscategorie gemiddeld samengaat met een slechter arbeidsmarktperspectief. Verder blijkt dat er, in tegenstelling tot het Rijk van Nijmegen, in de Achterhoek in verhouding tot Nederland duidelijk meer lager- en middelbaar opgeleiden zijn dan hoger opgeleiden. Alle wo-opleidingscategorieën zijn ondervertegen-woordigd en het aandeel van de meeste is zelfs meer dan de helft kleiner dan het Nederlandse. Voor alle wo-opleidingen behalve wo onderwijs gaat dit bovendien samen met gunstige arbeidsmarktperspectieven (lage ITA), in het bijzonder voor wo techniek. Hbo-opleidingscategorieën zijn meer verspreid over de kwadranten, met de grootste ondervertegenwoordiging in de werkgelegenheid voor hbo taal en cultuur en hbo gedrag en maatschappij.

Uitschieters aan de rechterzijde zijn mbo 2/3- en mbo 4 groen, waarvan het aandeel in de Achterhoek meer dan twee maal groter is dan in Nederland. Dit hangt samen met de uitgesproken Achterhoekse specialisatie in de sector landbouw, bosbouw en visserij. Ondanks het relatief kleine aandeel van de zorgsector zijn mbo $2 / 3$ - en mbo 4 zorg en welzijn ten slotte toch oververtegenwoordigd.

Tekstbox 1 Definities kernbegrippen

\begin{tabular}{|c|c|}
\hline Variabele & Definitie \\
\hline Uitbreidingsvraag & $\begin{array}{l}\text { Vraag naar nieuwe arbeidskrachten die ontstaat door de groei van de werkgelegenheid. Als er sprake is van een werkgelegenheidsdaling, is de } \\
\text { uitbreidingsvraag negatief. }\end{array}$ \\
\hline Vervangingsvraag & $\begin{array}{l}\text { Vervangingsvraag is de vraag naar nieuwe arbeidskrachten die ontstaat door bijvoorbeeld pensionering, (tijdelijke) uittreding vanwege zorgtaken, } \\
\text { arbeidsongeschiktheid, beroepsmobiliteit of doorstroom naar een andere opleiding. }\end{array}$ \\
\hline Arbeidsmarktuitstroom & De som van de vervangingsvraag en de negatieve uitbreidingsvraag. \\
\hline Arbeidsmarktinstroom & $\begin{array}{l}\text { De arbeidsmarktinstroom is het verwachte aanbod van nieuwe arbeidskrachten op de arbeidsmarkt. Deze is gebaseerd op de verwachte uitstroom van } \\
\text { schoolverlaters uit het initiële dag-, deeltijd-, niet-reguliere voltijdonderwijs en de beroepsgerichte volwasseneneducatie. Het weergegeven aanbod in de } \\
\text { figuren } 2 \text { en } 3 \text { is de instroom. Gecorrigeerd voor mobiliteitsstromen tussen arbeidsmarktregio's. }\end{array}$ \\
\hline Baanopeningen & $\begin{array}{l}\text { Baanopeningen zijn de totale vraag naar nieuwkomers op de arbeidsmarkt, zoals deze is bepaald door de werkgelegenheidsgroei (positieve uitbreidingsvraag) } \\
\text { en de vervangingsvraag. In de figuren } 2 \text { en } 3 \text { is dit de vraag naar arbeid. }\end{array}$ \\
\hline ITA & $\begin{array}{l}\text { Indicator Toekomstige Arbeidsmarktperspectief (ITA) van schoolverlaters en werkzoekenden. Deze indicator is gelijk aan een deling van het verwachte aanbod } \\
\text { door de verwachte vraag tot 2022. Naarmate de waarde van de ITA hoger ligt, is er sprake van een slechter arbeidsmarktperspectief. Een waarde tussen 1,01 en } \\
1,05 \text { duidt op een evenwichtssituatie. }\end{array}$ \\
\hline Typering ITA & $\begin{array}{l}\text { Een kwalitatieve beschrijving van de ITA. ITA } \leq 0,85 \text { wordt als "zeer goed" getypeerd, ITA }>0,85 \text { en } \leq 1,00 \text { als "goed", ITA }>1,00 \text { en } \leq 1,05 \text { als "redelijk", ITA }> \\
1,05 \text { en } \leq 1,15 \text { als "matig" en ITA }>1,15 \text { als "slecht". }\end{array}$ \\
\hline Typering loopbaan & $\begin{array}{l}\text { Het bruto uurloon van werkenden in de leeftijdsgroep 40-49 jaar ten opzichte van het bruto uurloon van werkenden in de leeftijdsgroep 20-29 jaar. Gemiddelde } \\
\text { cijfers voor Nederland in } 2016 \text {. }\end{array}$ \\
\hline Bruto uurloon & $\begin{array}{l}\text { Gemiddeld bruto uurloon van werknemers in euro's. Enquête Beroepsbevolking (EBB) gekoppeld aan het Sociaal Statistisch Bestand (SSB) van het jaar } 2016 . \\
\text { Gemiddelde cijfers voor Nederland in } 2016 .\end{array}$ \\
\hline Werkenden & Minimaal 1 uur werkzaam per week en in de leeftijd 15-74. Cijfers op basis van de Enquête Beroepsbevolking van het CBS. \\
\hline Werkzaamheid & Het percentage werkzaam is de werkzame beroepsbevolking als percentage van de potentiële beroepsbevolking (iedereen ouder dan 15 en jonger dan 75 jaar). \\
\hline Werkloosheid & $\begin{array}{l}\text { Percentage personen die geen betaald werk hebben, wel recent hebben gezocht en daarvoor direct beschikbaar zijn als percentage van de totale } \\
\text { beroepsbevolking (werkzaam en werkloos). }\end{array}$ \\
\hline Vast werk & Personen met een vast dienstverband. Percentage op basis van werknemers in de werkzame beroepsbevolking. \\
\hline Voltijds & Voltijdarbeid betreft personen die minstens 35 uur per week werkzaam zijn. Percentage op basis van de werkzame beroepsbevolking. \\
\hline Leeftijd & Gemiddelde leeftijd. \\
\hline Uren & Gemiddeld aantal uren werk per week. \\
\hline Student/scholier & Percentage van de werkenden met maatschappelijke positie student/scholier. \\
\hline Sectorspecialisatie & $\begin{array}{l}\text { De verhouding tussen het aandeel van het aantal werkenden in een sector in een bepaalde regio ten opzichte van het aandeel van die sector in Nederland. Een } \\
\text { sectorspecialisatiecoëfficiënt groter dan } 1 \text { impliceert dat het aandeel werkenden in de desbetreffende sector in de regio groter is dan in Nederland als geheel. }\end{array}$ \\
\hline Opleidingsspecialisatie & $\begin{array}{l}\text { De ratio van het aandeel personen met een bepaalde opleidingscategorie die wonen in een bepaalde regio ten opzichte van het aandeel van die } \\
\text { opleidingscategorie in het Nederlandse totaal. Indien de specialisatiecoëfficiënt voor een opleidingscategorie groter is dan 1, betekent dit dat de regio in } \\
\text { verhouding tot Nederland een groter aandeel van mensen met deze opleiding kent. }\end{array}$ \\
\hline
\end{tabular}


Tabel 1

Arbeidsmarktprognoses (2017-2022) en actuele arbeidsmarktcijfers (2015-2016) van de Achterhoek (AH) en Gelderland (GLD) naar opleidingsniveau*

\begin{tabular}{|c|c|c|c|c|c|c|c|}
\hline & bo/vmbo & havo/vwo & mbo $2 / 3$ & mbo 4 & hbo & wo & totaal \\
\hline \multicolumn{8}{|l|}{ Prognoses } \\
\hline Uitbreidingsvraag (\%) & 0,2 & 0,1 & 0,4 & 0,4 & 0,1 & 0,3 & 0,3 \\
\hline Vervangingsvraag (\%) & 3,5 & 2,3 & 2,1 & 1,6 & 3,2 & 5,9 & 2,8 \\
\hline Arbeidsmarktinstroom (\%) & 1,8 & 2,0 & 3,1 & 2,9 & 3,8 & 2,6 & 2,8 \\
\hline ITA (AH) & 0,94 & 1,02 & 1,07 & 1,08 & 1,05 & 0,87 & 1,02 \\
\hline Typering ITA (AH) & goed & redelijk & matig & matig & redelijk & goed & redelijk \\
\hline ITA (GLD) & 0,93 & 1,04 & 1,07 & 1,08 & 1,04 & 0,99 & 1,01 \\
\hline Typering ITA (GLD) & goed & redelijk & matig & matig & redelijk & goed & redelijk \\
\hline Typering loopbaan (NL) ${ }^{* *}$ & slecht & zeer goed & matig & redelijk & redelijk & goed & -- \\
\hline \multicolumn{8}{|l|}{ Actuele indicatoren } \\
\hline Bruto uurloon $(\mathrm{NL})^{* *}$ & 13,7 & 17,3 & 17,7 & 19,2 & 25,1 & 34,7 & -- \\
\hline Werkenden & 35.000 & 8.500 & 30.000 & 32.000 & 28.500 & 9.000 & 144.000 \\
\hline Werkzaamheid (\%) & 48 & 62 & 66 & 78 & 77 & 79 & 65 \\
\hline Werkloosheid (\%) & 4 & 5 & 6 & 3 & 3 & 3 & 4 \\
\hline Vast werk (\%) & 68 & 54 & 86 & 88 & 88 & 93 & 81 \\
\hline Voltijds (\%) & 41 & 37 & 54 & 55 & 57 & 66 & 52 \\
\hline Uren & 26,8 & 23,5 & 32,8 & 33,5 & 34,6 & 35,9 & 31,5 \\
\hline Leeftijd & 40,3 & 35,1 & 43,9 & 42,0 & 42,1 & 44,0 & 41,7 \\
\hline Student/scholier (\%) & 23 & 41 & 1 & 3 & 2 & 1 & 9 \\
\hline
\end{tabular}

'Prognoses als gemiddeld jaarlijks percentage van de werkzame beroepsbevolking in 2016; actuele indicatoren als percentage van de werkzame, totale of potentiële beroepsbevolking 2015-2016 (zie Tekstbox 1), tenzij anders aangegeven

** Lonen voor Nederland in 2016

Figuur 1

Actuele sectorspecialisatie van de Achterhoek ten opzichte van Nederland en Gelderland (gemiddeld over 2015-2016)

Landbouw, bosbouw en visserij Voedings- en genotmiddelenindustrie

Chemische industrie

Metaalindustrie

Overige industrie Energie

Bouwnijverheid Detailhandel Groothandel Vervoer en opslag Horeca

Informatie en communicatie

Financiële dienstverlening en onroerend goed Special istische zakelijke dienstverlening

Verhuur en overige zakelijke dienstverlening

Openbaar bestuur en overheidsdiensten Onderwijs$$
\text { Zorg }
$$

Welzijn

Cultuur sport en recreatie Overige dienstverlening, huishoudens en extraterritoriale organisaties

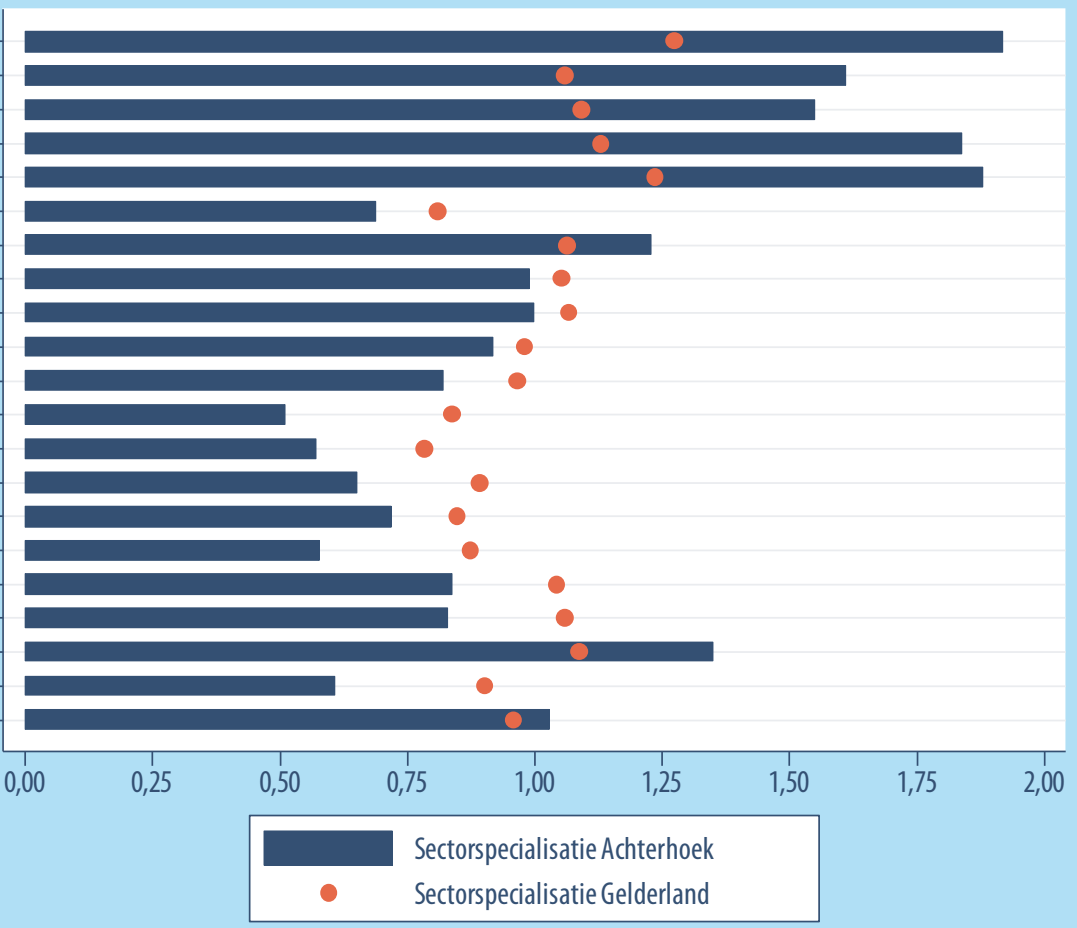




\section{Figuur 2}

Vraag en aanbod voor opleidingscategorieën lager/middelbaar (beroeps)onderwijs, de Achterhoek (2017-2022)

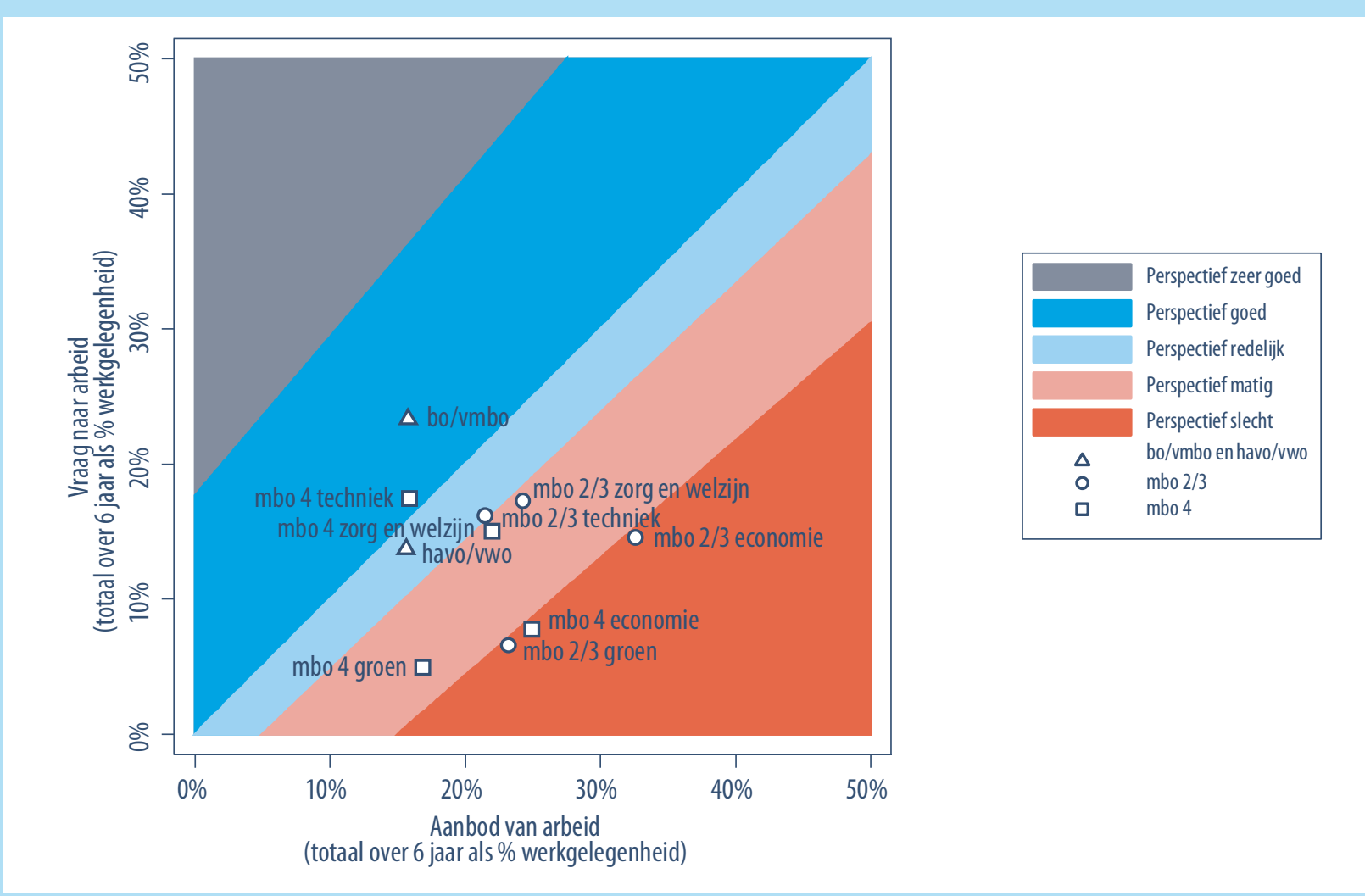

\section{Figuur 3}

Vraag en aanbod voor opleidingscategorieën hoger onderwijs, de Achterhoek (2017-2022)



\section{Figuur 4}

Arbeidsmarktperspectieven (ITA) versus specialisatie naar opleidingscategorie, de Achterhoek

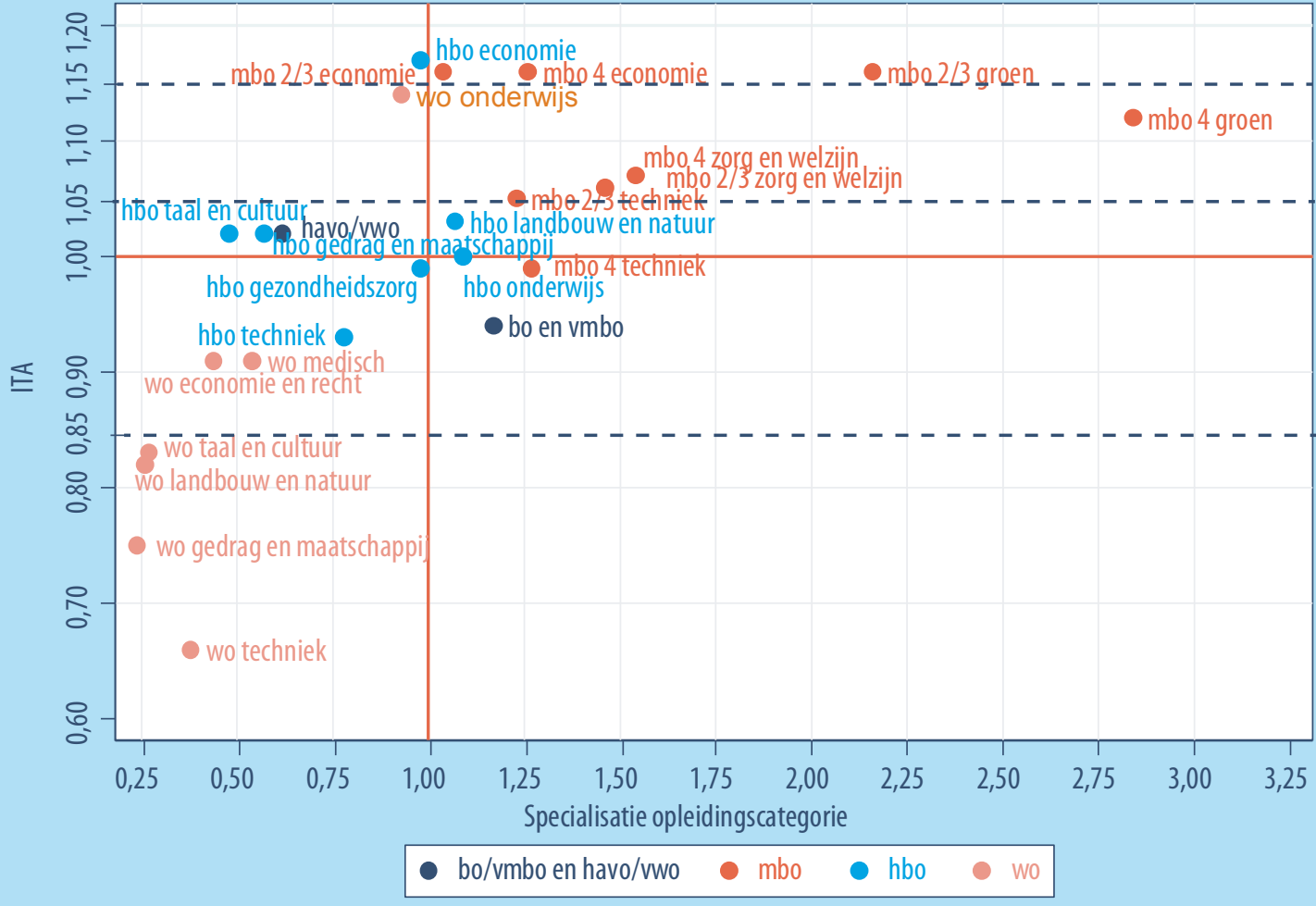




\section{Colofon}

( ) Researchcentrum voor Onderwijs en Arbeidsmarkt Niets uit deze uitgave mag op enige manier worden verveelvoudigd zonder voorafgaande schriftelijke toestemming van de directeur van het ROA.

Researchcentrum voor Onderwijs en Arbeidsmarkt

Maastricht University

School of Business and Economics

secretary-roa-sbe@maastrichtuniversity.nl

www.roa.n

\section{Vormgeving}

ROA secretariaat, Maastricht

juni 2018 